Original Research Article

\title{
Knowledge, attitude, practice of rational use of medicines among junior residents in a tertiary care hospital
}

\author{
Hooli Tanuja V., Srikanth*, Somashekara S. C., Suraj B.
}

Department of Pharmacology, ESIC Medical College, Gulbarga, Karnataka, India

Received: 02 June 2017

Accepted: 27 June 2017

\section{*Correspondence to: \\ Dr. Srikanth, \\ Email: pharmacsrikanth@ gmail.com}

Copyright: (C) the author(s), publisher and licensee Medip Academy. This is an openaccess article distributed under the terms of the Creative Commons Attribution NonCommercial License, which permits unrestricted noncommercial use, distribution, and reproduction in any medium, provided the original work is properly cited.

\begin{abstract}
Background: Irrational use of prescribing is on the rise due to many factors like false beliefs, following a prescribing pattern of senior doctors, inadequate knowledge, ignorance, promotional activities for the profit of professionals by pharmaceutical industry and lack of enforcement of regulations by regulatory authorities. Junior residents are exposed to variety of prescribing patterns in the first year and are the future physicians and specialists. There are very few studies among JRs, hence the present study was conducted to assess the knowledge, attitude and practice of junior residents about rational use of medicines.

Methods: This was a cross-sectional, questionnaire based study conducted among JRs at a tertiary care hospital in South India in June 2015. The participants were explained about the study and consent was taken. Permission was obtained from institutional ethics committee. Identity of the residents was kept confidential. A self-developed, pre-validated, semi-structured questionnaire consisting of both open-ended and closed-ended items was used. Questionnaire was designed to obtain information about the knowledge, attitude and practice of RUM. The data was recorded and analyzed using Microsoft Excel (2013 version) and the results are explained in frequency and percentage.

Results: The knowledge related to essential medicines list (EML), P drugs and schedule $\mathrm{H}$ drugs was limited. Participants had limited knowledge about the revision of EML list, number of fixed dose combinations (FDCs)in EML, STEP criteria for choosing a $\mathrm{P}$ drug and advantages of choosing a $\mathrm{P}$ drug Most of the JRs frequently prescribed drugs from EML. Trade name and newer drugs were prescribed around 50\%. The prescription of FDCs from EML was very low $(6 \%)$. Around $50 \%$ of JRs prescribe medicines with both generic and brand name.

Conclusions: Majority of JRs were aware about various issues concerned with RUM but the knowledge related to EML, P drugs, schedule $\mathrm{H}$ drugs and number of FDCs in EML was limited. As junior residents are future prescribers, they need to be aware of all the aspects of RUM. Inadequate/improper knowledge in the above areas is a matter of concern and needs to be addressed.
\end{abstract}

Keywords: Essential medicine list, KAP study, P-drugs, Rational use of medicine

\section{INTRODUCTION}

Rational use of medicines (RUM) as defined by World Health Organization (WHO) requires that patients receive medications appropriate to their clinical needs, in doses that meet their own requirements, for an adequate period of time, and at the lowest cost to them and their community. ${ }^{1}$ Irrational use of prescribing is on the rise due to many factors like false beliefs, following a prescribing pattern of senior doctors, inadequate knowledge, ignorance, promotional activities for the profit of professionals by pharmaceutical industry and lack of enforcement of regulations by regulatory authorities. ${ }^{2}$

Essential medicines list (EML) is an integral part of RUM and was defined by WHO in 1975 as a major step towards promoting RUM. ${ }^{3}$ The first WHO (EML) was published in 1977 with revisions every 2 years. In India, the Ministry of 
Health has revised the National List of Essential Medicines of India (NLEMI 2011) in 2015. It contains 376 medicines. ${ }^{4}$ EML have shown to improve the quality of prescribing and cost-effectiveness of health care delivery. ${ }^{5}$ Although majority of residents, students and doctors realize the importance of RUM, but application is lacking in their routine medical practice. ${ }^{6}$

Various studies have evaluated the perception of RUM among different groups like nurses, students, clinicians, pharmacists and prescribers. $^{7-9}$ Junior residents [JRs] are exposed to variety of prescribing patterns in the first year. JRs are the future physicians and specialists. Their attitude towards good prescribing and RUM will help in finding the lacunae among JR about the knowledge of RUM. There are very few studies among JR, hence the present study was conducted to assess the knowledge, attitude and practice of junior residents about RUM.

\section{METHODS}

This was a cross-sectional, questionnaire based study conducted among junior residents at a tertiary care hospital in South India in June 2015. The participants were explained about the study and consent was taken. Permission was obtained from institutional ethics committee. Identity of the residents was kept confidential. A self-developed, pre-validated, semi-structured questionnaire consisting of both open-ended and closedended items was used. Questionnaire was designed to obtain information about the knowledge, attitude and practice of RUM.

The questionnaire was first pre-tested in ten junior faculty and was suitably modified before distributing it to the participants. The final version of the questionnaire was distributed to the participants after explaining the nature and purpose of the study. Appropriate instructions about filling the questionnaire were given. The data was recorded and analyzed using Microsoft Excel (2013 version) and the results are explained in frequency and percentage.

\section{RESULTS}

Out of 154 junior residents, 147 completed the questionnaire and were included in the final analysis. Among the 147 JRs, 82 were males and 65 were females. The knowledge of RUM among JR is shown in Table 1.

The attitude and practice of RUM among JR is shown in Table 2 .

Table 1: Knowledge about RUM (n=147).

\begin{tabular}{|lll|}
\hline Statement & No. of respondents $(\%)$ \\
\hline Are you aware of the term RUM? & Yes & No \\
\hline Are you aware of the term essential medicines? & $123(83.6)$ & $24(16.4)$ \\
\hline Are you aware of the term P-drugs? & $118(80.2)$ & $29(19.8)$ \\
\hline When was the last EML list revised? (correct answer -Yes/No) & $93(63.2)$ & $54(36.8)$ \\
\hline Can you name the parts of a prescription? & $43(29.2)$ & $104(70.8)$ \\
\hline Are you aware of STEP criteria for selection of P-drug? & $39(26.5)$ & $108(73.5)$ \\
\hline Are you aware of advantages of using P-drug for prescription? & $15(10.2)$ & $132(89.8)$ \\
\hline Do you know the number of fixed dose combination included in EML? & $23(15.6)$ & $124(83.4)$ \\
\hline Are you aware of Schedule H drugs? & $9(6.1)$ & $138(93.9)$ \\
\hline Are you always aware of the ingredients of the drug you prescribe & $19(12.9)$ & $128(87)$ \\
\hline
\end{tabular}

RUM = Rational use of medicines, EML = Essential medicines list, STEP = Safety, tolerability, efficacy, price. The highest percentage of answers were for the knowledge of terms i.e. RUM and EML. Least percentage was for number of fixed dose combination in EML and STEP criteria for selecting P drugs.

\section{DISCUSSION}

The present study evaluates knowledge, attitude and practice about RUM in junior residents working at a tertiary care hospital. RUM contributes to maintaining high-quality health care, assessing knowledge of RUM among JRs will be helpful in promoting RUM and improving health care services. Knowledge is indicative understanding of a given subject. Attitude refers to feelings towards this subject and any preconceived ideas.
Their actions in which they demonstrate their knowledge and attitude constitutes practice. ${ }^{10}$

The knowledge of JRs about RUM is shown in Table 1. The knowledge related to EML, $\mathrm{P}$ drugs and schedule $\mathrm{H}$ drugs was limited. Participants had limited knowledge about the revision of EML list, number of FDCs in EML, STEP criteria for choosing a $\mathrm{P}$ drug and advantages of choosing a $\mathrm{P}$ drug. The findings are similar to other studies conducted on KAP of RUM, but in different faculties. ${ }^{11-13}$ 
Table 2: Attitude and practice about RUM (n=147).

\begin{tabular}{|c|c|c|}
\hline Statement & \multicolumn{2}{|c|}{ No. of respondents (\%) } \\
\hline \multirow{2}{*}{$\begin{array}{l}\text { Do you prescribe } \\
\text { essential medicines? }\end{array}$} & Yes & $105(71.4)$ \\
\hline & No & $42(28.6)$ \\
\hline \multirow{3}{*}{$\begin{array}{l}\text { How often do you } \\
\text { prescribe essential } \\
\text { medicines }\end{array}$} & Always & $26(17.6)$ \\
\hline & Frequently & $96(65.3)$ \\
\hline & Occasionally & $25(17)$ \\
\hline \multirow{3}{*}{$\begin{array}{l}\text { By which name do you } \\
\text { prescribe drugs }\end{array}$} & Generic & $53(36)$ \\
\hline & Trade name & $74(50)$ \\
\hline & Both & $20(13.6)$ \\
\hline \multirow{3}{*}{$\begin{array}{l}\text { How often do you } \\
\text { prescribe new drugs }\end{array}$} & Always & $29(19.7)$ \\
\hline & Frequently & $75(51)$ \\
\hline & Occasionally & $43(29.2)$ \\
\hline \multirow{2}{*}{$\begin{array}{l}\text { Do you think there } \\
\text { should be a EML in each } \\
\text { department }\end{array}$} & Yes & $126(85.7)$ \\
\hline & No & $21(14.3)$ \\
\hline \multirow{2}{*}{$\begin{array}{l}\text { Do you always prescribe } \\
\text { FDC from the EML }\end{array}$} & Yes & $9(6.1)$ \\
\hline & No & $138(93.9)$ \\
\hline \multirow{2}{*}{$\begin{array}{l}\text { Do you think regular } \\
\text { training is needed about } \\
\text { RUM after MBBS course }\end{array}$} & Yes & $129(87.7)$ \\
\hline & No & $18(12.3)$ \\
\hline
\end{tabular}

$\mathrm{EML}=$ Essential medicines list, $\mathrm{FDC}=$ Fixed dose combination, RUM $=$ Rational use of medicines

The primary purpose of EML is to promote RUM consisting OF the three important aspects, i.e., safety, efficacy and cost. Some studies have even reported that there is improvement in the quality of health care following use of EML and standard treatment guidelines. ${ }^{14}$ Hence, it is essential to adopt measures that will encourage their use.

The attitude and practice of RUM among JRs is shown in Table 2. Most of the JRs frequently prescribed drugs from EML. Trade name and newer drugs were prescribed around $50 \%$. The prescription of FDCs from EML was very low (6\%). Majority of the JRs agreed that there should be separate EML in each department and regular training should be conducted to students, JRs and clinicians. The findings are similar to other studies conducted on KAP of RUM, but in different faculties. ${ }^{11-13}$

Around $50 \%$ of JRs prescribe medicines with both generic and brand name. Various studies have revealed that prescribing medicines by brand name has become a routine practice. ${ }^{15,16}$ Recently Medical Council of India has notified that prescribing drugs should be with generic names and also ensure that there is rational prescribing. ${ }^{17}$ Prescribing by generic name will help to promote RUM. In this study, the percentage of JRs who are aware of Pdrug concept and practicing it, is less (63\% and 45\%). The reason might because of $\mathrm{P}$-drugs being a new concept in India has gained importance only in the last few years. ${ }^{18}$

Even though medical students are exposed to $\mathrm{P}$ drug concept in their second year (pharmacology curriculum), lack of knowledge regarding P-drug concept indicates that the P-drug concept has remained confined to pharmacology. Pharmacology is the only subject that deals with the rational use of medicine. There is an increasing concern about the pharmacology education in medical colleges as observed from high prescription errors by the junior doctors. Research showed that high incidence of drug prescribing errors is mainly due to inadequate pharmacology teaching. ${ }^{19-21}$

Although RUM is an important issue, but teaching of RUM is not given much importance in most of the medical colleges. $^{22}$ This is responsible major cause of errors in prescribing with its adverse consequences subsequently. ${ }^{23}$ WHO has suggested some measures for rational prescribing like continued emphasis on the inclusion of EML concept in undergraduate and post-graduate curriculum and emphasis on the effective utilization of drug committees at regional and district levels. ${ }^{24}$ This study provides an insight into the opinions and knowledge of various aspects of RUM in junior doctors which would be helpful in planning an intervention RUM.

\section{CONCLUSION}

Majority of JRs were aware about various issues concerned with RUM but the knowledge related to EML, $\mathrm{P}$ drugs, schedule $\mathrm{H}$ drugs and number of FDCs in EML was limited. As junior residents are future prescribers, they need to be aware of all the aspects of RUM. Inadequate/improper knowledge in the above areas is a matter of concern and needs to be addressed. Similar studies should be done at medical colleges, district hospitals and health care centers, so that the lacunae in knowledge, attitude and practice of RUM can be identified and appropriate corrective measures taken which will help in improving the quality of health care.

\section{ACKNOWLEDGEMENTS}

Authors would like to thank the participants of the study.

Funding: No funding sources

Conflict of interest: None declared

Ethical approval: The study was approved by the Institutional Ethics Committee

\section{REFERENCES}

1. World Health Organization: Guide to Good Prescribing, Geneva. World Health Organization. 1994;101-3.

2. Holloway K. Promoting rational use of medicines. Contact a publication of world council of churches. 2006;183:2-3.

3. The Selection of Essential Medicines-Perspectives WHO policies. 2002;1-6.

4. National list of essential medicines 2015 (India). Available http://cdsco.nic.in/WriteReadData/NLEM2015/Recommendations.pdf. Last accessed on 20th December 2016 at 9 pm. 
5. Manikandan S, Gitanjali B. National list of essential medicines of India: The way forward. J Postgr Med. 2012;58(1):68-72.

6. Patrício KP, Alves NA, Arenales NG, Queluz TT. Teaching the Rational Use of Medicines to medical students: A qualitative research. BMC Med Educ. 2012;12:56.

7. Toklu HZ, Demirdamar R, Gümüşel B, Ersin YE, Dülger G. Rational drug use awareness of the nurses in the Turkish republic of Northern Cyprus near east university hospital. Marmara Pharmaceutical Journal. 2012;16:150-4.

8. Kunda G, Thawani V, Sontakke S, Chaudhari K, Bankar M, Diwe R. Effect of information, education and communication intervention on awareness about rational pharmacy practice in pharmacy students. Indian Journal of Pharmacology. 2011;43(4):381-4.

9. Sankaravadivu T, Kumar SE, Bhavya E. A prospective study on rational drug use and the essential drug concept. International Journal of Research in Pharmaceutical and Biomedical Sciences. 2011;2(2):503-6.

10. Badran IG. Knowledge, attitude and practice the three pillars of excellence and wisdom: A place in the medical profession. Eastern Mediterranean Health Journal. 1995; 1:8-16.

11. Mahajan R, Singh NR, Singh J, Dixit A, Jain A, Gupta A. Current scenario of attitude and knowledge of physicians about rational prescription: A novel crosssectional study. J Pharm Bioalln Sci. 2010;2(2):132-6.

12. Bajait CS, Pimpalkhute SA, Sontakke SD, Dakhale GN, Jaiswal KM, Urade CS. Evaluation of knowledge, attitude and practice of rational use of medicines among clinicians in a tertiary care teaching hospital. Int J Nutr Pharmacol Neurol Dis. 2014;4:153-7.

13. Dakhale G, Pimpalkhute S, Bajait C, Raghute L. Evaluation of Knowledge, Attitude and Practice of Rational use of Medicine Among Interns and Resident Doctors in a Tertiary Care Teaching Hospital. J Young Pharm. 2016;8(2):114-7.

14. Hogerzeil HV. The concept of essential medicines: Lessons for rich countries. BMJ. 2004;329:1169-72.
15. Rathod R, Rathod A, Gupta VK, Ahmed T, Jha RK, Gaikwad N. Audit in Dermatology for Rational Prescribing. RJPBCS. 2012;3(3):518-24.

16. Abidi A, Gupta S, Kansal S. Prescription auditing and drug utilization pattern in a tertiary care teaching hospital of western UP. IJBCP. 2012;1(3):184-90.

17. Use of Generic name of drugs. Available at: http://www.mciindia.org/circulars/Public-NoticeGeneric-Drugs-21.04.2017.pdf. Last accessed on 5th May 2017 at $6 \mathrm{pm}$.

18. Parmar DM, Jadhav S. The concept of personal drugs in the undergraduate pharmacology practical curriculum. Indian J Pharmacol. 2007;39(3):165-7.

19. Gwee MC. Teaching of medical pharmacology: the need to nurture the early development of desired attitudes for safe and rational drug prescribing. Med Teach. 2009;31(9):847-54.

20. Oshikoya KA, Senbanjo IO, Amole OO. Interns knowledge ofclinical pharmacology and therapeutics after undergraduate and ongoinginternship training in Nigeria: a pilot study. BMC Medical Education. 2009;9(1):50.

21. Rothwell C, Burford B, Morrison J, Morrow G, Allen M, Davies C, et al. Junior doctors prescribing: enhancing their learning in practice. $\mathrm{Br} \mathrm{J}$ Clin Pharmacol. 2011;73(2):194-202.

22. De Vries TP, Henning RH, Horgerzeil HV, Fresle HV. World Health Organization: Guide to good prescribing. Geneva: WHO. 1994;14-8.

23. Maxwell S, Walley T, Ferner R. Using drugs safely. BMJ. 2002;324(7343):930-1.

24. World Health Organization. The Selection and Use of Essential Medicines-Report of the WHO Expert Committee. Geneva: WHO; 2011:8-9.

Cite this article as: Hooli TV, Srikanth, Somashekara SC, Suraj B. Knowledge, attitude, practice of rational use of medicines among junior residents in a tertiary care hospital. Int $\mathrm{J}$ Basic Clin Pharmacol 2017;6:2001-4. 